\title{
Activation of Escherichia coli Heat-Labile Enterotoxins by Native and Recombinant Adenosine Diphosphate-Ribosylation Factors, 20-kD Guanine Nucleotide-binding Proteins
}

\author{
Chii-Ming Lee, Patrick P. Chang, Su-Chen Tsai, Ronald Adamik, S. Russ Price, \\ Barbara C. Kunz, Joel Moss, Edda M. Twiddy, * and Randall K. Holmes* \\ Laboratory of Cellular Metabolism, National Heart, Lung, and Blood Institute, National Institutes of Health, Bethesda, Maryland \\ 20892; and *Department of Microbiology, Uniformed Services University of the Health Sciences, Bethesda, Maryland 20814
}

\begin{abstract}
Escherichia coli heat-labile enterotoxins (LT) are responsible in part for "traveler's diarrhea" and related diarrheal illnesses. The family of LTs comprises two serogroups termed LT-I and LT-II; each serogroup includes two or more antigenic variants. The effects of $L T s$ result from ADP ribosylation of $G_{s \alpha}$, a stimulatory component of adenylyl cyclase; the mechanism of action is identical to that of cholera toxin (CT). The ADP-ribosyltransferase activity of $\mathrm{CT}$ is enhanced by $20-\mathrm{kD}$ guanine nucleotide-binding proteins, known as ADP-ribosylation factors or ARFs. These proteins directly activate the CTA1 catalytic unit and stimulate its ADP ribosylation of $G_{s \alpha}$, other proteins, and simple guanidino compounds (e.g., agmatine). Because of the similarities between CT and LTs, we investigated the effects of purified bovine brain ARF and a recombinant form of bovine ARF synthesized in Escherichia coli on LT activity. ARF enhanced the LT-I-, LT-IIa-, and LT-IIb-catalyzed ADP ribosylation of agmatine, as well as the auto-ADP ribosylation of the toxin catalytic unit. Stimulation of ADP-ribosylagmatine formation by LTs and CT in the presence of ARF was GTP dependent and enhanced by sodium dodecyl sulfate. With agmatine as substrate, LT-IIa and LT-IIb exhibited $<1 \%$ the activity of CT and LT-Ih. CT and LTs catalyzed ADP-ribosyl$G_{s \alpha}$ formation in a reaction dependent on ARF, GTP, and dimyristoyl phosphatidylcholine/cholate. With $G_{s \alpha}$ as substrate, the ADP-ribosyltransferase activities of the toxins were similar, although CT and LT-Ih appeared to be slightly more active than LT-IIa and LT-IIb. Thus, LT-IIa and LT-IIb appear to differ somewhat from CT and LT-Ih in substrate specificity. Responsiveness to stimulation by ARF, GTP, and phospholipid/detergent as well as the specificity of ADP-ribosyltransferase activity are functions of LTs from serogroups LT-I and LT-II that are shared with CT. (J. Clin. Invest. 1991.87:17801786.) Key words: adenosine diphosphate ribosylation factor • cholera toxin • enterotoxins • quanine nucleotide-binding proteins
\end{abstract}

Mr. Chang's present address is Whittaker Bioproducts, 8830 Biggs Ford Road, Walkersville, MD 21793; Dr. Kunz's present address is Neue Zürcher Zeitung, Postfach CH-8021, Zürich, Switzerland.

Address reprint requests to Dr. Joel Moss, Section on Molecular Mechanisms, Laboratory of Cellular Metabolism, Building 10, Room 5N307, National Institutes of Health, Bethesda, MD 20892.

Received for publication 16 February 1989 and in revised form 27 December 1990.

The Journal of Clinical Investigation, Inc.

Volume 87, May 1991, 1780-1786

\section{Introduction}

Choleragen (cholera toxin [CT] $)^{1}$ and Escherichia coli heat-labile enterotoxin (LT) are responsible in part for cholera and "traveler's diarrhea," respectively (1-3). The abnormalities of fluid and electrolyte flux are caused by toxin-catalyzed ADP ribosylation of the stimulatory guanine nucleotide-binding protein of the hormone-sensitive adenylyl cyclase system, known as $G_{s \alpha}(4)$. This regulatory protein is normally active when GTP is bound. Inactivation of $\mathrm{G}_{\mathrm{s} \alpha}$ occurs when its intrinsic hydrolytic activity converts GTP to GDP (5); reactivation requires exchange of GDP for GTP, a process facilitated by agonist-receptor complexes. ADP ribosylation of $\mathrm{G}_{s \alpha}$ enhances its activity by inhibiting GTP hydrolysis, thereby prolonging the lifetime of the active $\mathrm{G}_{\mathrm{s} \alpha}$-GTP species (6), and by promoting release of GDP, which permits GTP binding (7) as well as the dissociation of $G_{s \alpha}$ from the inhibitory $G_{\beta \gamma}$ subunits $(8)$. It is ADP-ribosyl- $G_{s \alpha}-G T P$ that activates the cyclase catalytic unit and thereby accelerates conversion of ATP to cyclic AMP (5).

$\mathrm{CT}$ is an oligomeric protein consisting of one A and five B subunits; the $B$ subunits of $11.6 \mathrm{kD}$ are responsible for toxin binding to the cell surface (9). The A subunit of $29 \mathrm{kD}$ has latent ADP-ribosyltransferase activity; activation requires specific proteolysis and reduction of a disulfide bond, resulting in the formation of the $21-\mathrm{kD} \mathrm{A1}$, which is enzymatically active, and $\mathrm{A} 2$ of $8 \mathrm{kD}(9)$. The ADP-ribosyltransferase activity of CT is enhanced by $20-\mathrm{kD}$ membrane and soluble proteins, known as ADP-ribosylation factors or ARFs (10-12). The ARFs are guanine nucleotide-binding proteins (13) that are active in the presence of GTP or its analogues and inactive when GDP is bound (11-13). They interact directly with the A1 catalytic unit of toxin, enhancing its ability to catalyze the ADP ribosylation of $G_{s \alpha}$, proteins unrelated to the cyclase system, and simple guanidino compounds such as arginine and agmatine (14). The ARFs also enhance auto-ADP ribosylation of CTA1

1. Abbreviations used in this paper: ARF, ADP-ribosylation factor; similarly, rARF 2, recombinant bovine ARF 2 expressed in E. coli; and sARF I and sARF II, soluble 20-kD ARFs; CT, cholera toxin; CTA1, the Al protein of CT; DMPC, dimyristoyl phosphatidylcholine; $G_{s}$, the stimulatory guanine nucleotide-binding protein of the adenylyl cyclase system; $\mathrm{G}_{s \alpha}, \alpha$ subunit of $\mathrm{G}_{s} ; \mathrm{G}_{\beta \gamma}$, the $\beta \gamma$ subunits of the $\mathrm{G}$ protein; $\mathrm{LT}$, $E$. coli heat-labile enterotoxin; LT-Ih, heat-labile enterotoxin serogroup type I, encoded by plasmid from $E$. coli isolated from human; LT-Ip, heat-labile enterotoxin serogroup type I, encoded by plasmid from $E$. coli isolate from porcine; LT-IIa, $E$. coli heat-labile enterotoxin serogroup type II, variant a; LT-IIb, E. coli heat-labile enterotoxin serogroup type II, variant $b$. 
protein $(11,12)$. Guanine nucleotide binding by ARF and stimulation of toxin-catalyzed reactions were both enhanced by certain detergents (sodium dodecyl sulfate) and detergent/ phospholipids (cholate/dimyristoyl phosphatidylcholine) $(14,15)$.

LTs of the LT-I serogroup are similar to choleragen in subunit structure, immunological reactivity, enzymatic activity, and nucleotide and deduced amino acid sequences (9). Recently, the LT-II serogroup was defined, and two antigenic variants designated LT-IIa and LT-IIb were purified (16-19). Most strains of LT-II-producing $E$. coli have been isolated from animals (20); the relevance of LT-II to human disease is unclear. Nucleotide sequence analysis revealed that the genes encoding the A subunits of all toxins in the LT-I and LT-II serogroups are homologous $(21,22)$. The LT-I and LT-II subunit genes represent different branches of the LT family tree; LT-IIa and LT-IIb differ to a greater degree than do LT-Ih, LT-Ip, and CT $(19,21,22)$. Nevertheless, all members of this enterotoxin family increase intracellular cyclic AMP and it has been shown that CT, LT-Ih, and LT-IIa are ADP-ribosyltransferases $(17,23)$. Because of the considerable differences in deduced amino acid sequences of the A1 fragments of these toxins, however, we questioned whether the ARF regulatory site was conserved in the LT family. We describe here the conditions determined necessary for expression of the NAD: $G_{s \alpha}$ and NAD:agmatine ADP-ribosyltransferase activities of the LTs and the auto-ADP ribosylation of the $\mathrm{A} 1$ proteins as well as the effects of purified ARFs, GTP, detergents, and phospholipids on these enzymatic activities.

\section{Methods}

Materials. GTP, NAD, agmatine, thymidine, chicken albumin, and dimyristoyl phosphatidylcholine (DMPC) were purchased from Sigma Chemical Co., St. Louis, MO; sodium cholate from Calbiochem-Behring Corp., La Jolla, CA; dithiothreitol (DTT) from ICN Biomedicals, Costa Mesa, CA; trypsin and soybean trypsin inhibitor from Worthington Biochemical Corp., Freehold, NJ; sodium dodecyl sulfate (SDS), glycine, and AG1-X2 anion exchange resin from Bio-Rad Laboratories, Richmond, CA; cholera toxin and cholera toxin A subunit from List Biologicals, Campbell, CA; [adenylate- ${ }^{32} \mathrm{P}$ ]nicotinamide adenine dinucleotide $(30 \mathrm{Ci} / \mathrm{mmol})$ from Dupont New England Nuclear, Boston, MA; nicotinamide [U- ${ }^{14} \mathrm{C}$ ] adenine dinucleotide $(270-280 \mathrm{mCi}$ / mmol) from Amersham Corp., Arlington Heights, IL; urea, protein standards on SDS-polyacrylamide gels, and Tris from Bethesda Research Laboratories, Gaithersburg, MD). Standard proteins and their sizes are: myosin (H-chain), $200 \mathrm{kD}$; phosphorylase b, $97 \mathrm{kD}$; bovine albumin, $68 \mathrm{kD}$; ovalbumin, $43 \mathrm{kD}$; $\beta$-lactoglobulin, $18.4 \mathrm{kD}$; lysozyme, $14.3 \mathrm{kD}$; soybean trypsin inhibitor, $6.2 \mathrm{kD}$. AcA 54 was purchased from IBF Biotechnics, Columbia, MD; Sephadex G-75 and protein standards (as substrates) from Pharmacia Fine Chemicals, Piscataway, NJ. Protein standards are: phosphorylase b, $94 \mathrm{kD}$; bovine serum albumin, $67 \mathrm{kD}$; ovalbumin, $43 \mathrm{kD}$; carbonic anhydrase, $30 \mathrm{kD}$; soybean trypsin inhibitor, $21.1 \mathrm{kD}$; and $\alpha$-lactalbumin, $14.4 \mathrm{kD}$.

Purification of E. coli toxins. LT-Ih was purified from sonic extracts of $E$. coli HE22(pTD2) as previously described (17). LT-IIa and LT-IIb were purified as described $(17,18)$.

Purification of soluble $A R F(s A R F)$ and $G_{s} . \mathrm{SARF}$ was purified from bovine cerebral cortex (12). $\mathrm{G}_{\mathrm{s}}$ was purified from rabbit liver membranes by a modification of the procedure of Sternweis et al. (24).

Production and purification of recombinant bovine ARF 2 protein. A 1607-nucleotide EcoR1 restriction fragment of bovine retinal clone $2 B$ encompassing the ARF 2 coding region (25) was subcloned into the EcoR 1 site of the prokaryote expression vector pRC23 (26), which was used to transform $E$. coli strain RR1 bearing the plasmid pRK248cIts (27). In this system, expression is under the control of the phage $\lambda P_{L}$ promoter and regulated by a temperature-sensitive phage $\lambda$ cI repressor. Recombinant ARF 2 (rARF 2) protein was produced by switching the temperature of transformed bacteria at $A_{600}=0.5$ from $32^{\circ} \mathrm{C}$ to $42^{\circ} \mathrm{C}$ for $2 \mathrm{~h}$. The bacterial pellet from a $500-\mathrm{ml}$ culture was suspended in $2.5 \mathrm{ml}$ of $50 \mathrm{mM}$ Tris-Cl, pH 8.1/63 mM EDTA containing lysozyme, $1.5 \mathrm{mg} / \mathrm{ml}$, and incubated for $20 \mathrm{~min}$ at $4^{\circ} \mathrm{C}$. The cells were lysed by addition of $50 \mathrm{mM}$ Tris- $\mathrm{Cl}, \mathrm{pH} 8.1 / 63 \mathrm{mM}$ EDTA/0.5\% cholate $(2.5$ $\mathrm{ml}$ ) and incubated for $20 \mathrm{~min}$. The lysate supernatant $(\sim 5 \mathrm{ml})$ was applied to a column $(2 \times 120 \mathrm{~cm})$ of AcA 54 equilibrated and eluted with $20 \mathrm{mM}$ Tris-Cl, $\mathrm{pH} 7.4 / 0.25 \mathrm{M}$ sucrose/100 mM NaCl/1 mM EDTA/1 mM sodium azide/ $2 \mathrm{mM}$ DTT/1 mM phenylmethylsulfonyl fluoride/ $1 \mathrm{mM}$ benzamidine. The peak fractions of rARF 2 protein, identified by their ability to stimulate the ADP-ribosyltransferase activity of cholera toxin, were pooled, concentrated to $0.8 \mathrm{mg} / \mathrm{ml}$, and stored at $-30^{\circ} \mathrm{C}$. The protein was judged to be $\sim 90 \%$ pure by SDSPAGE.

Activation of toxins. CT as purchased is proteolytically nicked. Toxin $(10 \mu \mathrm{g})$ was activated by incubation $\left(30 \mathrm{~min}, 37^{\circ} \mathrm{C}\right)$ in $100 \mu \mathrm{l}$ of $50 \mathrm{mM}$ glycine, $\mathrm{pH} 8.0 / 20 \mathrm{mM}$ DTT. Incubation of CT with trypsin as described for LT-Ih or LT-IIb resulted in decreased basal and ARFstimulated activity (data not shown). LT-Ih and LT-IIb were activated as described for CT except that trypsin $(2 \mu \mathrm{g} / 10 \mu \mathrm{g}$ of LT-Ih; $20 \mu \mathrm{g} / 10$ $\mu \mathrm{g}$ of LT-IIb) was present, and incubation ( $30 \mathrm{~min}$ for LT-Ih, $120 \mathrm{~min}$ for LT-IIb) was terminated by addition of soybean trypsin inhibitor (4 and $40 \mu \mathrm{g}$, respectively). Trypsin inhibited both basal and ARF-stimulated activities of LT-IIa.

Assay-NAD:agmatine ADP-ribosyltransferase activity. Assays containing $50 \mathrm{mM}$ potassium phosphate (pH 7.5), $10 \mathrm{mM} \mathrm{MgCl}_{2}, 20 \mathrm{mM}$ DTT, $10 \mathrm{mM}$ agmatine, $0.6 \mu \mathrm{M}$ [adenine-U- ${ }^{14} \mathrm{C}$ ]NAD $(\sim 0.05 \mu \mathrm{Ci})$ and other additions as noted in figure legends were initiated with the indicated amount of activated toxins. After incubation at $30^{\circ} \mathrm{C}$ for the indicated time, duplicate samples were transferred to columns of AG1$\mathrm{X} 2(0.4 \times 4.5 \mathrm{~cm})$ which were washed five times with $1.0 \mathrm{ml}$ of distilled water as noted previously (28). Eluates containing [adenine- $\mathrm{U}-{ }^{14} \mathrm{C}$ ]ADP-ribosylagmatine were collected for radioassay. All assays were performed in duplicate and experiments were replicated at least three times.

Auto-ADP ribosylation of toxins and ADP ribosylation of $G_{s}$. Assays containing activated toxin, $50 \mathrm{mM}$ potassium phosphate ( $\mathrm{pH} 7.5), 10$ $\mathrm{mM} \mathrm{MgCl}{ }_{2}, 3 \mathrm{mM}$ DTT, $20 \mathrm{mM}$ thymidine, $10 \mu \mathrm{M}$ NAD, 1-3 $\mu \mathrm{M}$ $\left[{ }^{32} \mathrm{P}\right] \mathrm{NAD}(3 \mu \mathrm{Ci})$, and other indicated additions (total vol $=0.1 \mathrm{ml}$ ) were incubated at $30^{\circ} \mathrm{C}$ and terminated at the indicated time by addition of $25 \mu \mathrm{l}$ of ice-cold $50 \%$ trichloroacetic acid followed by $10 \mu \mathrm{l}$ of $1 \%$ bovine serum albumin. After precipitation at $4^{\circ} \mathrm{C}$ overnight and centrifugation $(10,000 \mathrm{~g}, 45 \mathrm{~min})$, protein pellets were dissolved in $60 \mathrm{mM}$ Tris/10\% glycerol/5\% 2-mercaptoethanol/3\% SDS/0.006\% bromophenol blue $\left(10 \mathrm{~min}, 65^{\circ} \mathrm{C}\right)$ and subjected to electrophoresis in $14 \%$ SDS-polyacrylamide gels (29). Kodak X-Omat AR films were used for autoradiography.

\section{Results}

The four heat-labile enterotoxins (CT, LT-Ih, LT-IIa, and LTIIb) were compared with regard to their ability to catalyze the ADP ribosylation of agmatine and $G_{s \alpha}$ and auto-ADP ribosylation of the toxin catalytic unit, with and without GTP, sARF, and/or detergent/phospholipid. Previous studies with sARF and CT demonstrated that DMPC/cholate in the absence of GTP did not significantly enhance ADP ribosylation (12). sARF and GTP dramatically increased toxin-catalyzed ADP ribosylation of $G_{s \alpha}$ (Fig. 1). In the presence of $s A R F$ and GTP, DMPC/cholate stimulated ADP ribosylation of $G_{s \alpha}$ by all four toxins (Fig. 1). rARF 2 also stimulated ADP ribosylation of $G_{s \alpha}$ in the presence of GTP (Fig. 2). Optimal ADP ribosylation of 

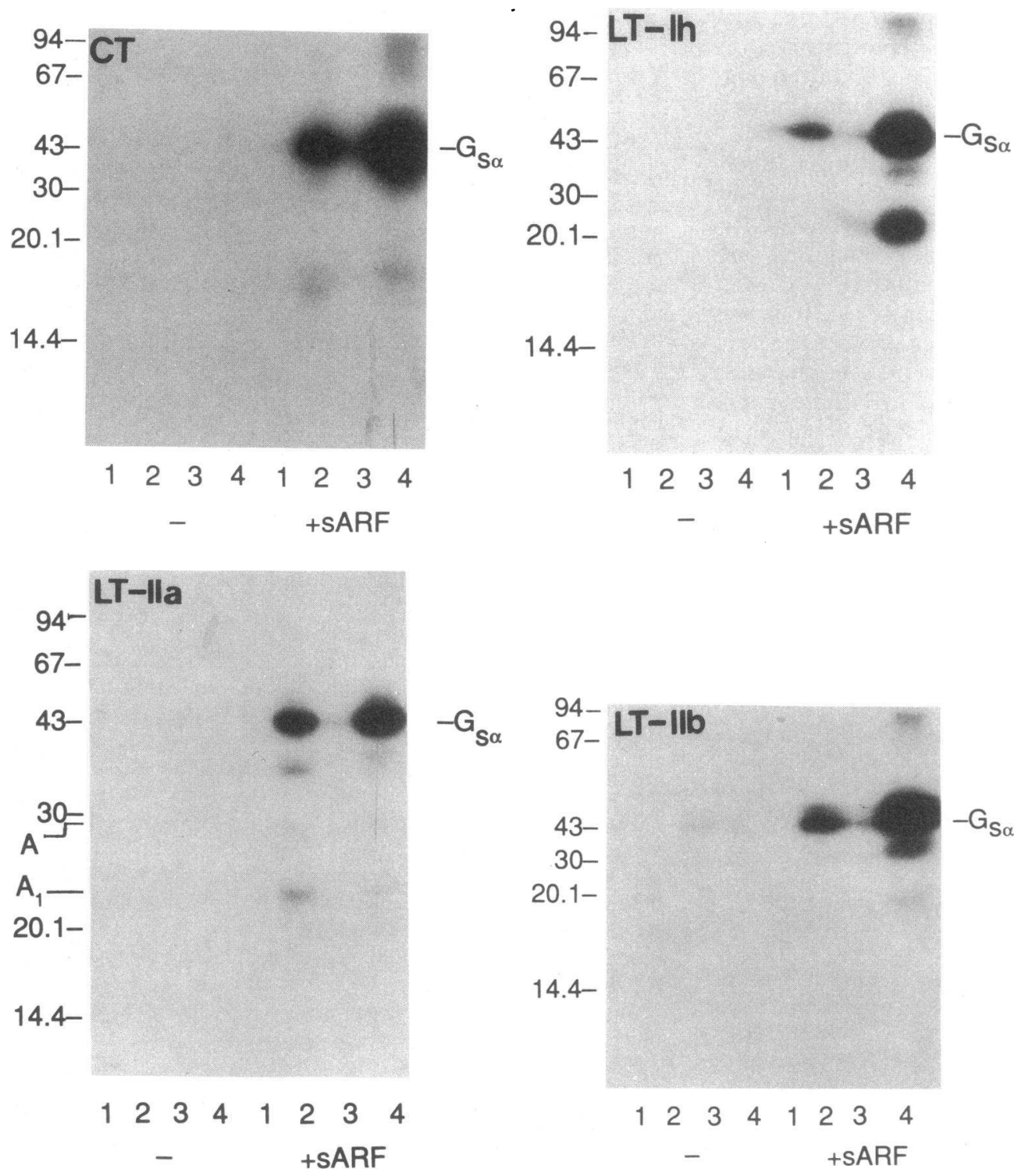

Figure 1. Effects of ARF, GTP, and DMPC/cholate on ADP ribosylation of $\mathrm{G}_{2 \alpha}$ catalyzed by CT and three LTs. CT $(600 \mu \mathrm{g} /$ $\mathrm{ml})$, LT-Ih $(600 \mu \mathrm{g} / \mathrm{ml})$, LT-IIa $(240 \mu \mathrm{g} / \mathrm{ml})$, and LT-IIb $(1.8$ $\mathrm{mg} / \mathrm{ml}$ ) were incubated in 50 $\mathrm{mM}$ glycine, pH 8.0/100 mM DTT $/ 0.01 \%$ trypsin for $15 \mathrm{~min}$ at $37^{\circ} \mathrm{C}$ (total vol $=0.1 \mathrm{ml}$ ). After addition of PMSF (10 $\mu \mathrm{l}$; final concentration $=80 \mathrm{mM}$ ), samples of toxins (CT, $3 \mu \mathrm{g}$; LTIh, $3 \mu \mathrm{g}$; LT-IIa, $8.4 \mu \mathrm{g}$; LT-IIb, $9 \mu \mathrm{g})$ were incubated with purified $\mathrm{G}_{3}(0.1 \mu \mathrm{g})$ for assay of ADP ribosylation of $\mathrm{G}_{\varepsilon \alpha}$ as described in Methods. Lane 1, buffer; Lane 2, $100 \mu$ M GTP; Lane 3, 1 mM DMPC $/ 0.06 \%$ cholate; Lane 4 , GTP plus DMPC/cholate without or with SARF-I $(1 \mu \mathrm{g})$.

$\mathrm{G}_{\mathrm{s} \alpha}$ was dependent on trypsinization of LT-Ih (Fig. 3). CT used in these studies was proteolyzed, giving rise to CTA1 and CTA2; Mekalanos et al. (30) had shown previously that trypsinization of CTA resulted in a significant increase in enzymatic activity. ADP ribosylation of $\mathrm{G}_{\mathrm{s} \alpha}$ was time dependent; under limiting reaction conditions, similar rates of ADP ribosylation were observed with all four toxins (Fig. 4).

In the NAD:agmatine ADP-ribosyltransferase assay (Fig. 5), all four toxins responded to SARF and GTP with increased catalytic activity. Neither SARF nor GTP was effective alone. In all cases, the effect of SARF plus GTP was enhanced by SDS (Fig. 5). The activities of LT-IIa and LT-IIb, both basal and with optimal sARF stimulation (in the presence of GTP and SDS) were $<1 \%$ those of LT-Ih or CT. In the presence of DMPC/cholate and rARF 2, conditions used to optimize the ADP ribosylation of $\mathrm{G}_{s \alpha}$, ADP-ribosylagmatine formation by CT and LT-Ih was also much greater than that observed with LT-IIa and LT-IIb (Fig. 6). The presence of trypsin and trypsin inhibitor in the final assay was not responsible for the differences in activity.
Auto-ADP ribosylation of CTAl and the A1 fragments of LT-IIa and LT-IIb in the presence of DMPC/cholate was dependent on or stimulated by rARF 2 . In the absence of ARF, there was significant auto-ADP ribosylation of intact LT-Ih A subunit, which was slightly stimulated by rARF 2 (Fig. 7). In contrast, auto-ADP ribosylation of LT-Ih A1 protein was dependent to a much greater extent on rARF 2 (Fig. 3). rARF 2 appeared to be both an activator of toxin and a toxin substrate (Fig. 7). In the presence of rARF 2 both ADP ribosylation of exogenous proteins (protein standards) and auto-ADP ribosylation of the toxin catalytic units were significantly greater by CT and LT-Ih than by LT-IIa or LT-IIb (Fig. 8). Auto-ADP ribosylation of CTA1 was decreased by the addition of exogenous protein substrates.

Under two sets of conditions, with DMPC/cholate or with SDS, and with rARF 2 and SARF, the relative activities of the toxins in the NAD:agmatine, NAD:protein, and NAD:G $\mathbf{G}_{\mathbf{s} \alpha}$ ADP ribosylation assays were significantly different. In the NAD:agmatine ADP ribosylation assay, under conditions identical to those used for the ADP ribosylation of $\mathrm{G}_{\mathrm{s} \alpha}$ (except 


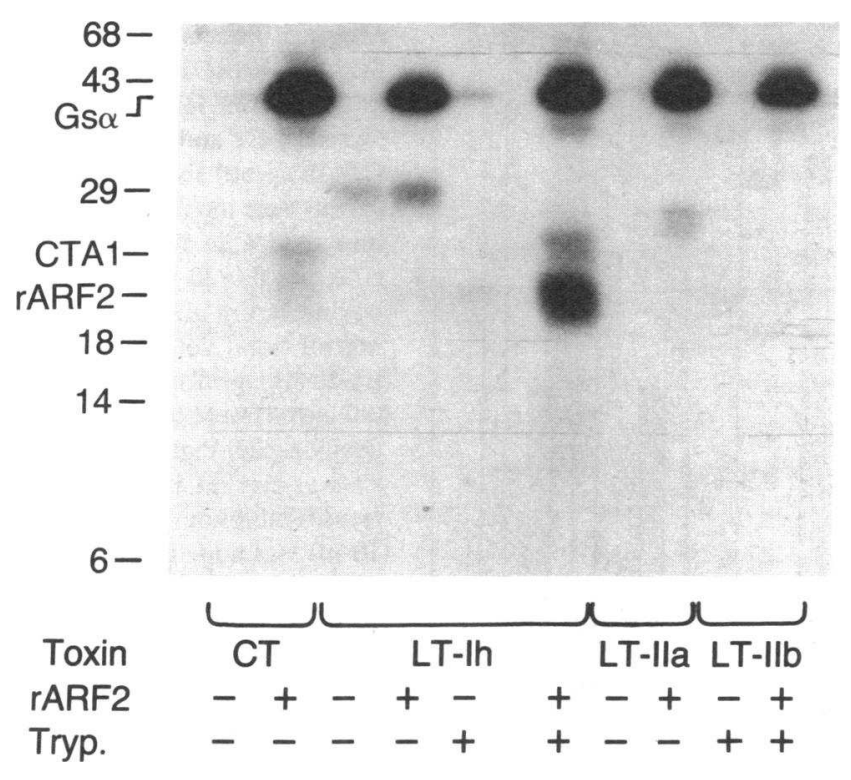

Figure 2. Effect of rARF 2 on ADP ribosylation of $\mathrm{G}_{\mathbf{s} \alpha}$ catalyzed by CT and three LTs in the presence of DMPC/cholate. Toxins $(2 \mu \mathrm{g})$ activated as described in Methods, were incubated for $4 \mathrm{~h}$ at $30^{\circ} \mathrm{C}$ with additions to the assay of $\mathrm{G}_{\mathrm{s}}(0.1 \mu \mathrm{g}), 100 \mu \mathrm{M}$ GTP, $0.9 \mathrm{mM}$ DMPC $/ 0.06 \%$ sodium cholate without or with rARF $2(2 \mu \mathrm{g})$. Tryp. refers to incubations performed with trypsin/trypsin inhibitor. Exposure time for autoradiogram was $6 \mathrm{~h}$.

for the absence of $\mathrm{G}_{\mathrm{s} \alpha}$ and the addition of agmatine), CT and LT-Ih exhibited significantly more activity than did LT-IIa or LT-IIb.

\section{Discussion}

Initial studies of LT-I isolated from $E$. coli strains of either human or porcine origin demonstrated significant structural, functional, and immunological similarities to CT $(2,9,31-34)$. More recent studies by Holmes and co-workers revealed that some $E$. coli strains produce enterotoxins (LT-IIa, LT-IIb) that are antigenically distinct and differ significantly in amino acid sequences from LT-I or CT, although they also cause elevation of intracellular cyclic AMP $(17,19,21,22)$. Based on comparison of toxin nucleotide sequences, it was hypothesized that the A subunits of all toxins in the LT family originated from a common ancestral gene, with separate branches leading to the LT-I and LT-II serogroups $(21,22)$. Comparison of deduced

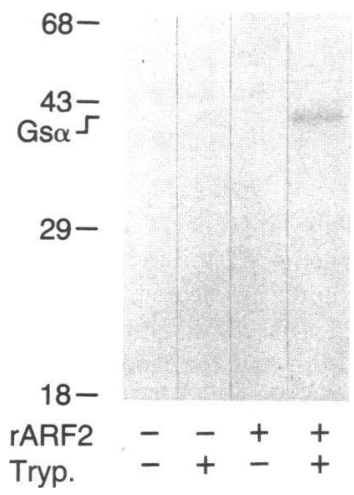

Figure 3. Effect of trypsin activation and IARF 2 on ADP ribosylation of $\mathrm{G}_{\mathrm{sa}}$ by LT-Ih. LT-Ih $(0.75 \mu \mathrm{g})$, activated with or without trypsin as described in Methods, was incubated with $\mathrm{G}_{\mathrm{s}}(0.05 \mu \mathrm{g})$ at $30^{\circ} \mathrm{C}$ for $3 \mathrm{~min}$ without or with rARF $2(0.75 \mu \mathrm{g})$ in reaction buffer (see Methods) plus 0.9 $\mathrm{mM} \mathrm{DMPC} / 0.06 \%$ sodium cholate and $0.1 \mathrm{mM}$ GTP.

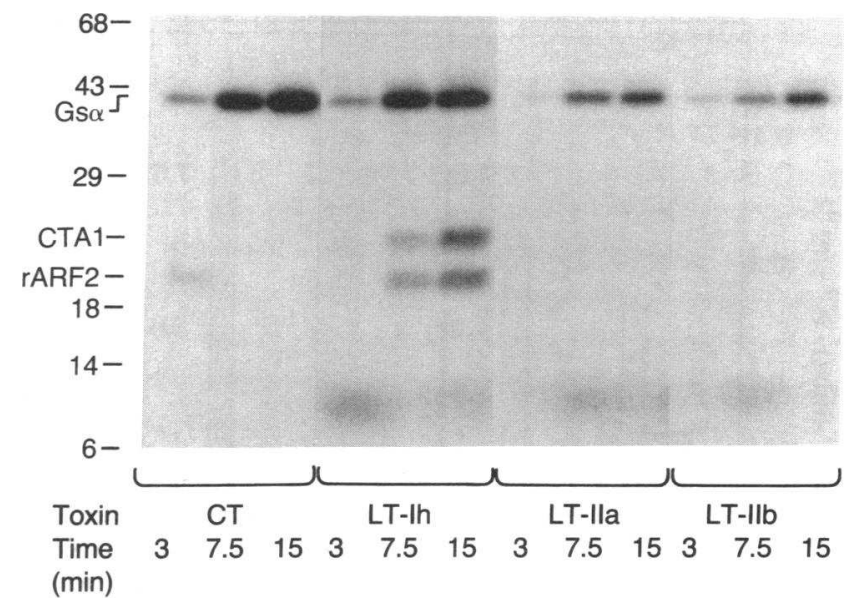

Figure 4. ADP ribosylation of $\mathrm{G}_{\mathrm{s} \alpha}$ by $\mathrm{CT}$ and three $\mathrm{LTs}$ in the presence of DMPC/cholate. Toxins $(0.75 \mu \mathrm{g}$, activated as described in Methods) were incubated with rARF $2(0.75 \mu \mathrm{g})$ at $30^{\circ} \mathrm{C}$ in reaction buffer (see Methods) with $0.1 \mathrm{mM} \mathrm{GTP}, 0.9 \mathrm{mM}$ DMPC/0.06\% sodium cholate, and $\mathrm{G}_{\mathrm{s}}(0.1 \mu \mathrm{g})$ (total volume $\left.100 \mu \mathrm{l}\right)$. Reactions containing CT, LT-Ih, LT-IIa, or LT-IIb as indicated were terminated at $3,7.5$, or $15 \mathrm{~min}$ and assayed for [ ${ }^{32} \mathrm{P}$ ]ADP-ribosyl-G $\mathrm{s}_{\mathrm{s \alpha}}$ formation as described in Methods. Positions of standard proteins are as shown.

amino acid sequences of toxin $\mathrm{A} 1, \mathrm{~A} 2$, and $\mathrm{B}$ polypeptides revealed that $\mathrm{A} 1$, in particular the amino terminus of $\mathrm{A} 1$, is conserved to the greatest extent $(21,22)$.

Earlier data and present results establish that CT, LT-Ih, LT-IIa, and LT-IIb all possess ADP-ribosyltransferase activity and the capacity to use either proteins or simple guanidino compounds as ADP-ribose acceptors $(9,23,31,35)$. Thus, the catalytic site is conserved. CT and LT-Ih exhibited much higher activities with agmatine as an ADP-ribose acceptor than did LT-IIa or LT-IIb. With exogenous proteins as substrates also, the activities of CT and LT-Ih were much higher than LT-IIa and LT-IIb. The differences in activity were observed both in SDS and DMPC/cholate. The latter conditions were identical to those used to ADP-ribosylate $\mathrm{G}_{\mathrm{s} \alpha}$; under these conditions and with $G_{s \alpha}$ as substrate, the activities of the toxins appear to be much more similar although LT-IIa and LT-IIb were still less active than CT or LT-Ih. These studies are compatible with the hypothesis that the toxins do differ, at least quantitatively, in substrate specificity. In particular, LT-IIa and LT-IIb are much less active towards model substrates (i.e., simple guanidino compounds) than CT or LT-Ih. The fact that the toxins exhibit differences in catalytic activity may reflect some differences in the structure of the active sites in the Al fragments, perhaps effects of the A2 fragments, or differences in susceptibilities to trypsin activation or inactivation. The fact that some transferases that modify arginine residues in proteins utilize simple guanidino compounds whereas others do not most likely reflects differences in the catalytic subunits.

Earlier studies demonstrated enhancement of all CT-catalyzed reactions by $20-\mathrm{kD}$ guanine nucleotide-binding ARF proteins in the presence of GTP and either SDS or DMPC/cholate $(11,12,14,15)$. As shown here, LT-Ih, LT-IIa, and LT-IIb also respond to ARF plus GTP with increases in their NAD:agmatine, NAD:G $\mathrm{G}_{s \alpha}$, and NAD:A1 ADP-ribosyltransferase activities. The fact that GTP was necessary in each instance supports the specificity of the ARF effects. One of the major advantages 


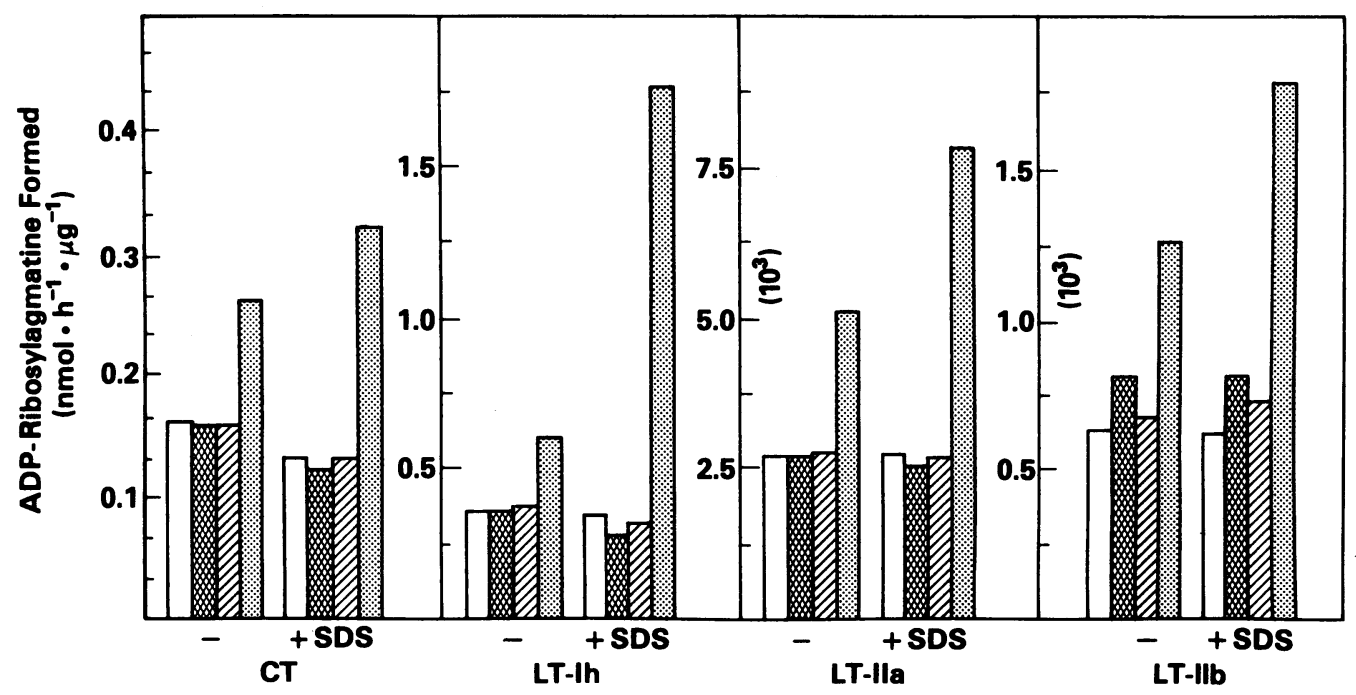

Figure 5. Effects of GTP, SDS, and SARF on ADP-ribosylagmatine formation catalyzed by CT and three LTs. CT $(10 \mu \mathrm{g} / \mathrm{ml})$ and LT-IIa (80 $\mu \mathrm{g} / \mathrm{ml})$ were incubated for 10 min at $37^{\circ} \mathrm{C}$ in $50 \mathrm{mM}$ glycine, $\mathrm{pH}$ 8.0/20 mM DTT/ bovine serum albumin, 1 $\mathrm{mg} / \mathrm{ml}$ (total volume $90 \mu \mathrm{l}$ ). LT-Ih $(10 \mu \mathrm{g} / \mathrm{ml})$ and LT-IIb $(80 \mu \mathrm{g} / \mathrm{ml})$ were treated identically except that $0.1 \%$ trypsin was present and soybean trypsin inhibitor $(100 \mu \mathrm{g}$ in $10 \mu \mathrm{l})$ was added at the end of the 10-min incubation. Samples of toxins (CT, $1 \mu \mathrm{g}$; LT-Ih, $1 \mu \mathrm{g}$; LT-IIa, $8 \mu \mathrm{g}$; LT-IIb, $8 \mu \mathrm{g}$ ) were then assayed for NAD:agmatine

ADP-ribosyltransferase activity in the presence of $0.1 \mathrm{mM}$ NAD with buffer (open bars), $100 \mu \mathrm{M}$ GTP (double cross-hatched bars), sARF-II, 2 $\mu \mathrm{g}$ (cross-hatched bars), or GTP plus sARF-II (speckled bars) and $0.003 \%$ SDS (as indicated) for $4 \mathrm{~h}$ (CT and LT-Ih) or $16 \mathrm{~h}$ (LT-IIa and LT-IIb) at $30^{\circ} \mathrm{C}$ (total vol $=0.3 \mathrm{ml}$ ). In the panels describing LT-IIa and LT-IIb, $10^{3}$ on the ordinate indicates that the activities were multiplied by $10^{3}$ to obtain values comparable to those noted with CT and LT-Ih. Data are means of values from four experiments. Standard errors (not shown) were $<5 \%$ of mean values.

of studying the auto-ADP-ribosyltransferase and NAD:agmatine ADP-ribosyltransferase reactions is that modification of these activities by ARF is likely to reflect directly its effects on toxin rather than on $\mathrm{G}_{\mathrm{s} \alpha}$. The data presented here provide

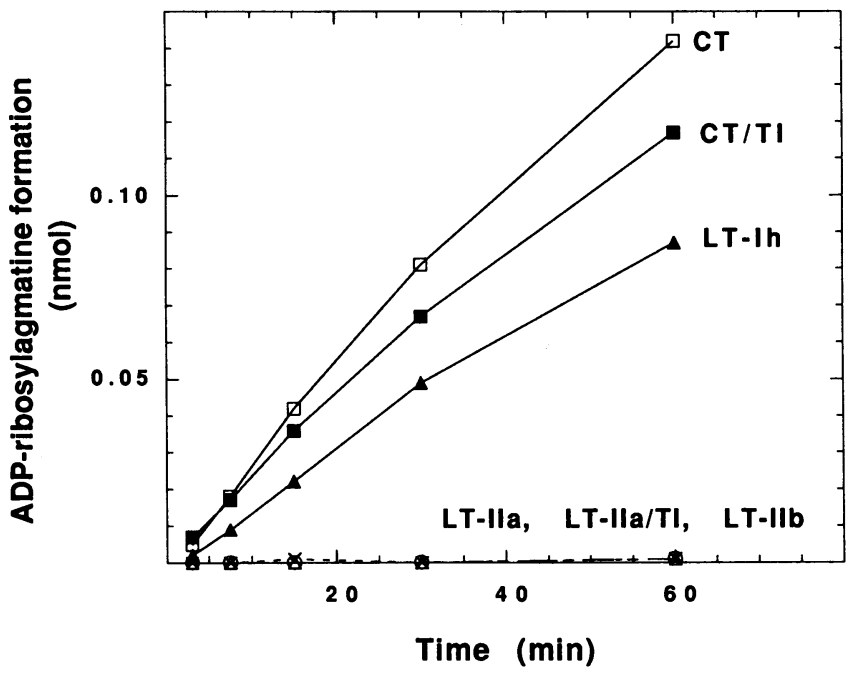

Figure 6. ADP-ribosylagmatine formation catalyzed by CT and LT-Ih in the presence of rARF 2 . Toxins $(0.75 \mu \mathrm{g}$, activated as described in Methods) and rARF $2(0.75 \mu \mathrm{g})$ plus $50 \mathrm{mM}$ potassium phosphate (pH 7.5), $10 \mathrm{mM} \mathrm{MgCl}, 3 \mathrm{mM}$ DTT, $20 \mathrm{mM}$ thymidine, $0.1 \mathrm{mM}$ GTP, $10 \mu \mathrm{M}$ NAD, $2 \mu \mathrm{M}$ [adenine- $\mathrm{U}-{ }^{14} \mathrm{C}$ ]NAD $(0.05 \mu \mathrm{Ci}), 0.9 \mathrm{mM}$ DMPC/0.06\% sodium cholate, and $10 \mathrm{mM}$ agmatine (total vol 150 $\mu$ l) were incubated at $30^{\circ} \mathrm{C}$ for $3,7.5,15,30$, or 60 min before removal of duplicate 50- $\mu$ l samples for separation of ADP-ribosylagmatine. To determine whether differences in activity might reflect the presence of trypsin and soybean trypsin inhibitor (TI), CT and LT-Ila were activated as noted in Methods and where indicated (CT/ TI, LT-IIa/TI), trypsin $(1.5 \mu \mathrm{g})$ and TI $(3 \mu \mathrm{g})$ were added to the activation mixture before removal of sample for assay. strong evidence that the regulatory ARF sites and the catalytic domains are conserved in all members of the LT toxin family, consistent with the hypothesis that both sites are important for toxin function.

In most cases, the ARF (plus GTP) effects were amplified by detergents and/or phospholipids. The ARF - GTP-stimulated NAD:agmatine ADP-ribosyltransferase activities of all the toxins were enhanced by SDS. Auto-ADP ribosylation of CT, LT-I, and LT-IIa, but not LT-IIb, was also stimulated by SDS (data not shown). The ARF - GTP-dependent ADP ribosylation of $G_{s \alpha}$ was increased further by DMPC/cholate. Since
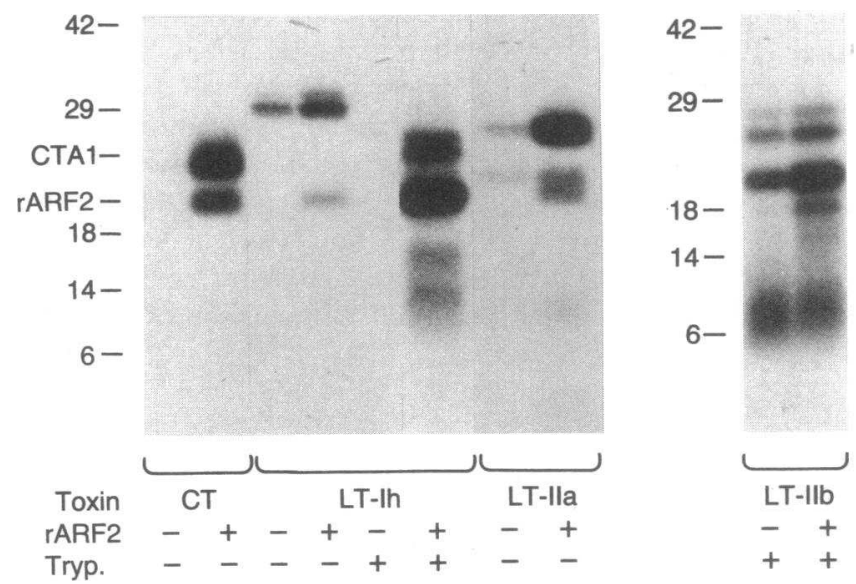

Figure 7. Effect of rARF 2 on auto-ADP ribosylation of CT and LTs in the presence of DMPC/cholate. Toxins activated and incubated as in Fig. 2 except for the absence of $G_{s}$, and as indicated, with CT $(2 \mu \mathrm{g})$; LT-Ih $(2 \mu \mathrm{g}$, not trypsin-activated); LT-Ih $(2 \mu \mathrm{g}$, trypsin-activated); LT-IIa (8 $\mu \mathrm{g})$; LT-IIb (16 $\mu \mathrm{g})$. Exposure time for experiments with CT, LT-Ih, and LT-IIa was $24 \mathrm{~h}$ whereas that for LT-IIb, was $7 \mathrm{~d}$. The exposure times for autoradiograms and toxin concentrations differ from those used in the experiments described in Fig. 2. 


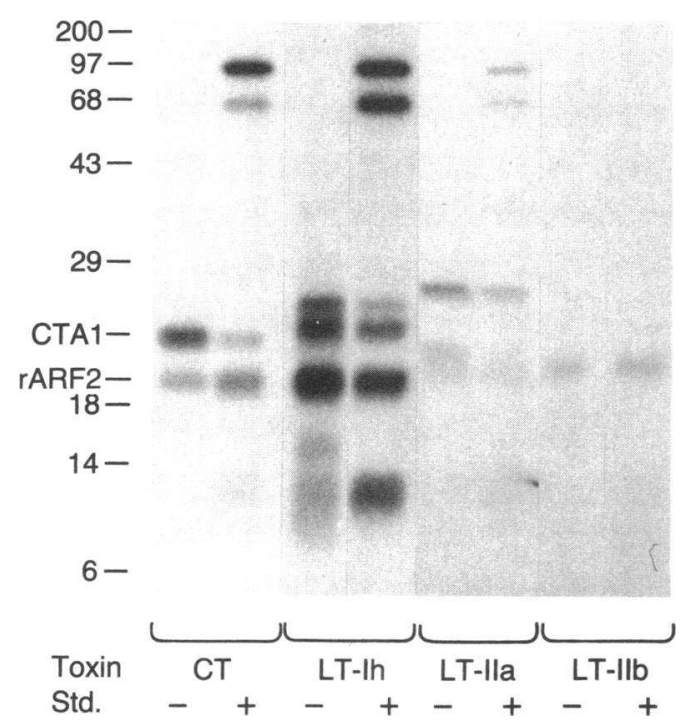

Figure 8. Auto-ADP ribosylation and ADP ribosylation of protein standards by $C T$ and LTs. Toxins were activated and incubated with rARF $2(2 \mu \mathrm{g})$ as in Fig. 2, except for omission of $\mathrm{G}_{3}$. Protein standards (5 $\mu \mathrm{g}$ of each protein) were added as additional substrates as indicated (Std.). CT $(4 \mu \mathrm{g})$, LT-Ih $(4 \mu \mathrm{g})$, LT-IIa $(12 \mu \mathrm{g})$, and LT-Ilb $(12 \mu \mathrm{g})$ were present as noted in the figure.

DMPC/cholate appears to be necessary for the high affinity binding of GTP by ARF (15), it is not clear whether it influences the interaction between ARF.GTP and toxin. In the presence of DMPC/cholate, LT-Ih A subunit exhibited considerably more auto-ADP ribosylation activity than did the A1 fragment of LT-Ih. Furthermore, the auto-ADP ribosylation of LT-Ih A subunit was only poorly responsive to the rARF 2 protein, whereas auto-ADP ribosylation of the LT-Ih Al fragment was much more dependent on ARF. In the NAD:G s $_{s}$ assay, the unnicked form was virtually inactive whereas the nicked form was much more active and also responsive to recombinant ARF.

The B (or binding) subunits of the LT toxins are more diverse in amino acid sequence than are the Al proteins $(21,22)$, consistent with observations that the toxins apparently bind to different molecules on the cell surface (17). Ganglioside $G_{1}$ is the site of CT binding $(9,36)$; LT-Ih is believed to use $\mathrm{GM}_{1}$ as well as glycoproteins $(31,37-42)$. LT-IIa and LT-IIb may also bind to gangliosides, but their specificities differ from those of $\mathrm{CT}$ and $\mathrm{LT}$, in agreement with the differences in primary structure of the B subunits $(17,21,22,43-45)$. The several A2 peptides differ considerably in amino acid sequence $(19,21,22,44$, 46). The $A 2$ peptide is believed to be involved in association of the Al protein with the B oligomer and in the case of CT, has been proposed to play a role in the translocation of the Al protein through the cell membrane $(9,47,48)$. These putative activities have not been quantified. Obviously, however, preservation of A2 function is not necessarily inconsistent with considerable diversity at the amino acid level.

In sum, the A1 proteins of the LT family have highly conserved amino acid sequences and share catalytic activity as well as the ability to be stimulated by ARF.GTP, although they differ in specificities for $G_{s \alpha}$ and agmatine as substrates. The domains of A1 responsible for these activities remain to be defined. The amino acid sequence of the amino terminal region of the Al subunits exhibit some similarity to that of the pertussis toxin S1 subunit, which is also an ADP-ribosyltransferase and in which this region is critical for enzymatic activity as shown by in vitro mutagenesis (49-51). A similar approach may aid in identification of the domains of CT and the LTs that are involved in catalytic activity and in activation by ARF.

\section{Acknowledgments}

We thank Mrs. Carol Kosh for expert secretarial assistance.

This study was supported in part by Public Health Service grant AI-14107 from the National Institute of Allergy and Infectious Disease, National Institutes of Health. Dr. Kunz was supported in part by the Branco Weiss Foundation, Zürich, Switzerland.

\section{References}

1. Finkelstein, R. A. 1973. Cholera. CRC Crit. Rev. Microbiol. 2:553-623.

2. Field, M. 1979. Mechanisms of action of cholera and Escherichia coli enterotoxins. Am. J. Clin. Nutr. 32:189-196.

3. Kelly, M. T. 1986. Cholera: a worldwide perspective. Ped. Infect. Dis. 5:S101-S105.

4. Moss, J., D. L. Burns, J. A. Hsia, E. L. Hewlett, R. L. Guerrant, and M. Vaughan. 1984. Cyclic nucleotides: mediators of bacterial toxin action in disease. Ann. Intern. Med. 101:653-666.

5. Gilman, A. G. 1987. G proteins: transducers of receptor-generated signals. Annu. Rev. Biochem. 56:615-649.

6. Cassel, D., and Z. Selinger. 1977. Mechanism of adenylate cyclase activation by cholera toxin: inhibition of GTP hydrolysis at the regulatory site. Proc. Natl. Acad. Sci. USA. 74:3307-3311.

7. Burns, D. L., J. Moss, and M. Vaughan. 1982. Choleragen-stimulated release of guanyl nucleotides from turkey erythrocyte membranes. J. Biol. Chem. 257:32-34.

8. Kahn, R. A., and A. G. Gilman. 1984. ADP-ribosylation of $\mathrm{G}_{\mathrm{s}}$ promotes the dissociation of its $\alpha$ and $\beta$ subunits. J. Biol. Chem. 259:6235-6240.

9. Moss, J., and M. Vaughan, 1988. ADP-ribosylation of guanyl nucleotidebinding regulatory proteins by bacterial toxins. Adv. Enzymol. 61:303-379.

10. Kahn, R. A., and A. G. Gilman. 1984. Purification of a protein cofactor required for ADP-ribosylation of the stimulatory regulatory component of adenylate cyclase by cholera toxin. J. Biol. Chem. 259:6228-6234.

11. Tsai, S.-C., M. Noda, R. Adamik, J. Moss, and M. Vaughan. 1987. Enhancement of choleragen ADP-ribosyltransferase activities by guanyl nucleotides and a 19-kDa membrane protein. Proc. Natl. Acad. Sci. USA. 84:5139-5142.

12. Tsai, S.-C., M. Noda, R. Adamik, P. P. Chang, H.-C. Chen, J. Moss, and M. Vaughan. 1988. Stimulation of choleragen enzymatic activities by GTP and two soluble proteins purified from bovine brain. J. Biol. Chem. 263:1768-1772.

13. Kahn, R. A., and A. G. Gilman. 1986. The protein cofactor necessary for ADP-ribosylation of $\mathrm{G}_{\mathbf{s}}$ by cholera toxin is itself a GTP binding protein. J. Biol. Chem. 261:7906-7911.

14. Noda, M., S.-C. Tsai, R. Adamik, J. Moss, and M. Vaughan. 1990. Mechanism of cholera toxin activation by a guanine nucleotide-dependent 19-KDa protein. Biochim. Biophys. Acta. 1034:195-199.

15. Bobak, D. A., M. M. Bliziotes, M. Noda, S.-C. Tsai, R. Adamik, and J. Moss. 1990. Mechanism of activation of cholera toxin by ADP-ribosylation factor (ARF): both low- and high- affinity interactions of ARF with guanine nucleotides promote toxin activation. Biochemistry. 29:855-861.

16. Guth, B. E. C., C. L. Pickett, E. M. Twiddy, R. K Holmes, T. A. T Gomes, A. A. M. Lima, R. L. Guerrant, B. D. G. M. Franco, and L. R. Trabulsi. 1986. Production of type II heat-labile enterotoxin by Escherichia coli isolated from food and human feces. Infect. Immun. 54:587-589.

17. Holmes, R. K., E. M. Twiddy, and C. L. Pickett. 1986. Purification and characterization of type II heat-labile enterotoxin of Escherichia coli. Infect. Immun. 53:464-473.

18. Guth, B. E. C., E. M. Twiddy, L. R. Trabulsi, and R. K. Holmes. 1986 Variation in chemical properties and antigenic determinants among type II heatlabile enterotoxins of Escherichia coli. Infect. Immun. 54:529-536.

19. Pickett, C. L., E. M. Twiddy, B. W. Belisle, and R. K. Holmes. 1986. Cloning of genes that encode a new heat-labile enterotoxin of Escherichia coli. J. Bacteriol. 165:348-352.

20. Seriwatana, J., P. Echeverria, D. N. Taylor, L. Rasrinaul, J. E. Brown, J. S. M. Peiris, and C. L. Clayton. 1988. Type II heat-labile entero-toxin produc- 
ing Escherichia coli isolated from animals and humans. Infect. Immun. 56:11581161.

21. Pickett, C. L., D. L. Weinstein, and R. K. Holmes. 1987. Genetics of type IIa heat-labile enterotoxin of Escherichia coli: operon fusions, nucleotide sequence, and hybridization studies. J. Bacteriol. 169:5180-5187.

22. Pickett, C. L., and R. K. Holmes. 1990. Nucleotide sequence of Escherichia coli heat-labile enterotoxins type Ila and IIb and comparisons to type I enterotoxin and cholera toxin. In Advances in Research in Cholera and Related Diarrheas, R. B. Sack and Y. Zinnaka editors. Volume 7. KTK Scientific Publishers, Tokyo, Japan. 165-171.

23. Chang, P. P., J. Moss, E. M. Twiddy, and R. K. Holmes. 1987. Type II heat-labile enterotoxin of Escherichia coli activates adenylate cyclase in human fibroblasts by ADP-ribosylation. Infect. Immun. 55:1854-1858.

24. Sternweis, P. C., J. K. Northup, M. D. Smigel, and A. G. Gilman. 1981. The regulatory component of adenylate cyclase. J. Biol. Chem. 256:1151711526.

25. Price, S. R., M. Nightingale, S.-C. Tsai, K. C. Williamson, R. Adamik, H.-C. Chen, J. Moss, and M. Vaughan. 1988. Guanine nucleotide-binding proteins that enhance choleragen ADP-ribosyltransferase activity: Nucleotide and deduced amino acid sequence of an ADP-ribosylation factor cDNA. Proc. Natl. Acad. Sci. USA. 85:5488-5491.

26. Crowl, R., C. Seamons, P. Lomedico, and S. McAndrews. 1985. Versatile expression vectors for high-level synthesis of cloned gene products in Escherichia coli. Gene. 38:31-38.

27. Bernard, H.-U, E Remaut, M. V. Hershfield, H K Das, and D. R Helinski. 1979. Construction of plasmid cloning vehicles that promote gene expression from the bacteriophage lambda $P_{L}$ promoter. Gene. 5:59-76.

28. Moss, J., and S. J. Stanley. 1981. Histone-dependent and histone-independent forms of an ADP-ribosyltransferase from human and turkey erythrocytes. Proc. Natl. Acad. Sci. USA. 78:4809-4812.

29. Laemmli, U. K. 1970. Cleavage of structural proteins during the assembly of the head of bacteriophage T4. Nature (Lond.). 227:680-685.

30. Mekalanos, J. J., R. J. Collier, and W. R. Romig. 1979. Enzymic activity of cholera toxin. II. Relationships to proteolytic processing, disulfide bond reduction, and subunit composition. J. Biol. Chem. 254:5855-5861.

31. Moss, J., J. C. Osborne, Jr., P. H. Fishman, S. Nakaya, and D. C. Robertson. 1981. Escherichia coli heat-labile enterotoxin. J. Biol. Chem. 256:1286112865 .

32. Gyles, C. L. 1974. Relationships among heat-labile enterotoxins of Escherichia coli and Vibrio cholerae. J. Infect. Dis. 129:277-283.

33. Clements, J. D., and R. A. Finkelstein. 1978. Demonstration of shared and unique immunological determinants in enterotoxins from Vibrio cholerae and Escherichia coli. Infect. Immun. 22:709-713.

34. Dallas, W. S., and S. Falkow. 1980. Amino acid sequence homology between cholera toxin and Escherichia coli heat-labile enterotoxin. Nature (Lond.). 288:499-501.

35. Mekalanos, J. J., R. J. Collier, and W. R. Romig. 1979. Enzymic activity of cholera toxin. I. New method of assay and the mechanism of ADP-ribosyl transfer. J. Biol. Chem. 254:5849-5854.

36. Fishman, P. H. 1980. Mechanism of action of cholera toxin: events on the cell surface. In Secretory Diarrhea. M. Field, J. S. Fordtran, and S. G. Schultz, editors. American Physiological Society, Bethesda, MD. 85-106.

37. Holmgren, J. 1973. Comparison of the tissue receptors for Vibrio cholerae and Escherichia coli enterotoxins by means of gangliosides and natural cholera toxoid. Infect. Immun. 8:851-859.

38. Pierce, N. F. 1973. Differential inhibitory effects of cholera toxoids and ganglioside on the enterotoxins of Vibrio cholera and Escherichia coli. J. Exp. Med. 137:1009-1023.

39. Moss, J., S. Garrison, P. H. Fishman, and S. H. Richardson. 1979. Gangliosides sensitize unresponsive fibroblasts to Escherichia coli heat-labile enterotoxin. J. Clin. Invest. 64:381-384.

40. Holmgren, J., P. Fredman, M. Lindblad, Svennerholm, A. M. and Svennerholm, L. 1982. Rabbit intestinal glycoprotein receptor for Escherichia coli heat-labile enterotoxin lacking affinity for cholera toxin. Infect. Immun. 38:424433.

41. Holmgren, J., M. Lindblad, P. Fredman, L. Svennerholm, and H. Myrvold. 1985. Comparison of receptors for cholera and Escherichia coli enterotoxins in human intestine. Gastroenterology. 89:27-35.

42. Griffiths, S. L., R. A. Finkelstein, and D. R. Critchley. 1986. Characterization of the receptor for cholera toxin and Escherichia coli heat-labile toxin in rabbit intestinal brush borders. Biochem. J. 238:313-322.

43. Lai, C.-Y. 1977. Determination of the primary structure of cholera toxin B subunit. J. Biol. Chem. 252:7249-7256.

44. Mekalanos, J. J., D. J. Swartz, G. D. N. Pearson, N. Harford, F. Groyne, and M. de Wilde. 1983. Cholera toxin genes: nucleotide sequence, deletion analysis and vaccine development. Nature (Lond.). 306:551-557.

45. Fukuta, S., J. L. Magnani, E. M. Twiddy, R. K. Holmes, and V. Ginsburg. 1988. Comparison of the carbohydrate-binding specificities of cholera toxin and Escherichia coli heat-labile enterotoxins LTh-I, LT-IIa, and LT-IIb. Infect. Immun. 56:1748-1753.

46. Spicer, E. K., W. M. Kavanaugh, W. S. Dallas, S. Falkow, W. H. Konigsberg, and D. E. Schafer. 1981. Sequence homologies between A subunits of Escherichia coli and Vibrio cholerae enterotoxins. Proc. Natl. Acad. Sci. USA. 78:5054

47. Gill, D. M. 1976. The arrangement of subunits in cholera toxin. Biochemistry. 15:1242-1248.

48. Wisnieski, B. J., and J. S. Bramhall. 1981. Photolabelling of cholera toxin subunits during membrane penetration. Nature (Lond.). 289:319-321.

49. Locht, C., and J. M. Keith. 1986. Pertussis toxin gene: nucleotide sequence and genetic organization. Science (Wash. DC). 232:1258-1264.

50. Cieplak, W., W. N. Burnette, V. L. Mar, K. T. Kaljot, C. F. Morris, K. K. Chen, H. Sato, and J. M. Keith. 1988. Identification of a region in the S1 subunit of pertussis toxin that is required for enzymatic activity and that contributes to the formation of a neutralizing antigenic determinant. Proc. Natl. Acad. Sci. USA. 85:4667-4671.

51. Nicosia, A., M. Perugini, C. Franzini, M. C. Casagli, M. G. Borri, G. Antoni, M. Almoni, P. Neri, G. Ratti, and R. Rappuoli. 1986. Cloning and sequencing of the pertussis toxin genes: operon structure and gene duplication. Proc. Natl. Acad. Sci. USA. 83:4631-4635. 